\title{
Starch and talc emboli in drug addicts' lungs
}

\author{
D. LAMB AND G. ROBERTS ${ }^{1}$ \\ From the Departments of Pathology and Forensic Medicine, St George's Hospital Medical School, London
}

SYNOPSIS The lungs of eight drug addicts dying as a consequence of their habit have been examined. All showed the presence of small amounts of talc emboli and five the presence of starch emboli. $\stackrel{\circ}{\circ}$ Talc was invariably associated with a marked foreign body reaction which was insignificant in $\overrightarrow{\vec{\omega}}$ association with starch. Animal experiments showed very rapid (90\% in 24 hours) removal of $\stackrel{\omega}{\sigma}$ maize starch emboli; such rapid removal in man would explain the lack of a foreign body response. $\frac{\overline{0}}{0}$ Quantitation of the amount of starch present in lungs from two of the cases gave values of 1.5 and i $5 \cdot 2 \mathrm{~g}$. The higher amount could have been a contributory factor in the sudden death of the addict. The amounts of talc seen were not sufficient to be of clinical significance.

Drug addicts are known to inject themselves with a variety of pharmaceutical preparations many of which were not intended for parenteral administration. Tablets are crushed or capsules opened, the resulting powder is mixed with water, and the suspension injected. Fashions vary and over the last three years in Great Britain there has been a vogue for injecting barbiturate preparations intravenously (Glatt, 1969).

In addition to the pharmacologically active constituents, tablets and capsules contain a variety of other substances, which may be insoluble, whose function is either to aid in the manufacture or to assist disintegration when taken orally. The substances of main interest in the context of this paper are talc used as a lubricant in the manufacturing process and occasionally as a filler, and starch, usually maize starch, which is widely used as a binder, lubricant, filler, and disintegrant (Davis, 1961 ; British Pharmacopoea, 1968).

We have examined the lungs of eight addicts who died as a consequence of their habit, all of whom were administering drugs intravenously. Fragments of talc were identified in all eight lungs but the most obvious extraneous material identified in five of the eight cases was starch. All five showed high blood barbiturate levels.

These substances (talc and starch) when injected intravenously lodge in the small pulmonary arteries or capillaries of the alveolar walls. Talc has been shown to produce vascular lesions of a severity sufficient to cause pulmonary hypertension, in some cases leading to death in cor pulmonale (Krainer, ${ }^{1}$ Now at NIH, Washington.

Received for publication 3 August 1972.
Berman, and Wishnick, 1962; Wendt, Puro, Shapiro, $\vec{\circ}$ Mathews, and Wolf, 1964; Puro, Wolf, Skingandas, and Vazquez, 1966; Hahn, Schweid, and Beaty, 1969; 음 Butz, 1969; Hopkins and Taylor, 1970). Starch, $\stackrel{\mathbb{C}}{-}$ though identified either alone or with talc, has $\overrightarrow{0}$ received only passing mention (Puro et al, 1966; N Hahn et al, 1969; Butz, 1969).

Though starch provokes a much milder tissua response than talc it may produce a clinical important foreign body reaction in the peritoneum (Lee and Lehman, 1947; Lee, Collins, and Lahgen, 1952; Paine and Smith, 1957; Myers, Deaver, and Brown, 1960). No evidence for such a marked response was seen in the lungs of the drug addicts we examined. To assist in the interpretation of our findings in the drug addicts an experimental study of the natural history of maize starch emboli in the rat was performed.

\section{Materials and Methods}

\section{HUMAN LUNGS}

The lungs of five addicts dying in the London area were collected intact and fixed by inflation with $4 \% \frac{7}{0}$ buffered formaldehyde in saline. Incomplete portions of lungs were received from three further cases; $N$ these could not be fixed by inflation.

The volume of the inflated lungs was determined $N$ by water displacement. The lungs were then cut into $\omega$ $1 \mathrm{~cm}$ slices and blocks taken to include both normak looking areas and the areas of patchy haemorrhage seen in three cases. Blocks of kidney were examined $\stackrel{\mathbb{D}}{\oplus}$ for starch granules that might have passed through ${ }_{7}^{+}$ the lung capillary bed.

Tissue was processed over 48 hours, embedded in 
paraffin and cut at $5 \mu$. Sections were stained with haematoxylin and eosin and by a reticulin technique.

Special stains for starch were not used routinely as identification using polarized light proved more useful.

Quantitation of the number of starch grains present in two of the lungs involved the method detailed by Aherne (1967) for particles of small diameter using a Zeiss integrating eyepiece where

$\begin{aligned} & \text { Number of objects in volume } \\ & \text { quantitated }\end{aligned}=A \frac{2 n \text { Vp }}{\left(\frac{c}{n} d+2 t\right)}$

where $\mathrm{n}=$ number of objects counted, $\mathrm{Vp}=$ volume of tissue corrected for shrinkage in processing, $\mathbf{A}=$ area scanned, $c=$ number of transepts, $d=$ distance apart of parallel lines on integrating eyepiece, and $t=$ section thickness.

A suspension of the maize starch used in the animal injections was examined using a white cell counting chamber and $1 \mathrm{~g}$ of starch was found to contain about $88 \times 10^{7}$ starch grains.

\section{RAT EXPERIMENTS}

Preliminary work showed that $40 \mathrm{mg}$ of starch injected intravenously into a $250 \mathrm{~g}$ rat was usually fatal within minutes and a dose of $\mathbf{3 0 ~} \mathrm{mg}$ occasionally so.

Forty female SPF rats (Carworth Europe), each weighing $250 \mathrm{~g}$, were given a single intravenous injection of $10 \mathrm{mg}$ of starch suspended in $0.2 \mathrm{ml}$ sterile saline. Injection was into a superficial leg vein through a $1 \mathrm{~cm}$ skin incision under nembutal anaesthesia $(30 \mathrm{mg} / \mathrm{kg})$. The maize starch used was a sample of that used in manufacturing tablets and capsules kindly supplied by Eli Lilly.
Groups of rats were killed at periods of 15 minutes, six hours, 24 hours, two days, four days, and seven days after the injection. The lungs were fixed by inflation with formaldehyde saline and longitudinal sections of the left lung prepared and stained as for the human tissue. The lungs of five rats from the same stock but without starch injection were used as controls.

Quantitation of starch grains in the rat lungs was done by a simple count of starch grains seen in $\mathbf{2 0 0}$ high-power fields $(0.3 \mathrm{~mm}$ diameter $)$ using polarized light to identify the starch. The results were recorded as starch grains per 10 high-power fields.

Toxicological analysis in the case of the drug addicts, using gas chromatography of blood and urine, was carried out by the Department of Forensic Medicine at St George's Hospital Medical School.

\section{Results}

Brief details of the eight addicts are included in Table I. All eight were 'found dead' by friends or members of the public and in three cases there was evidence that death followed immediately after an intravenous injection. All eight cases were males.

The five intact lungs were more extensively examined with 10 blocks from each. In the other three cases the pathologist had selected areas showing macroscopic abnormality at necropsy and only two or three blocks of tissue were available from these cases. Macroscopically none of the lungs showed any emphysema or significant scarring. Patchy oedema was present in three lungs and obvious alveolar haemorrhage in three, including two with pulmonary oedema. Inhalation of vomit is sometimes incriminated as a cause of sudden death in such

\begin{tabular}{|c|c|c|c|c|c|}
\hline Case & Age & Lungs Inflated & $\begin{array}{l}\text { Foreign Material in Lung } \\
\text { Recognized with Polarized Light }\end{array}$ & Blood Barbiturate & Urine Analysis \\
\hline $1^{1}$ & 25 & Yes & $\begin{array}{l}\text { Abundant starch } \\
\text { Talc present }\end{array}$ & $3.6 \mathrm{mg}$ & Methadone \\
\hline $2^{1}$ & 23 & No & $\begin{array}{l}\text { Abundant starch } \\
\text { Talc trace }\end{array}$ & $\begin{array}{l}3.5 \mathrm{mg} \\
\text { Quinalbarbitone } \\
\text { Amylobarbitone }\end{array}$ & $\begin{array}{l}\text { Morphine } \\
\text { Methadone }\end{array}$ \\
\hline 3 & 25 & Yes & $\begin{array}{l}\text { Starch present } \\
\text { Talc trace }\end{array}$ & $\begin{array}{l}0.8 \mathrm{mg} \\
\text { Pentobarbitone }\end{array}$ & $\begin{array}{l}\text { Methadone } \\
\text { Paracetamol }\end{array}$ \\
\hline 4 & 20 & Yes & $\begin{array}{l}\text { Starch nil } \\
\text { Talc present }\end{array}$ & ? Trace & Methadone \\
\hline $5^{1}$ & 20 & Yes & $\begin{array}{l}\text { Abundant starch } \\
\text { Talc trace }\end{array}$ & $\begin{array}{l}3.8 \mathrm{mg} \\
\text { Amylobarbitone }\end{array}$ & Alcohol \\
\hline 6 & 21 & No & $\begin{array}{l}\text { Starch present } \\
\text { Talc trace }\end{array}$ & $1.0 \mathrm{mg}$ & Alcohol \\
\hline 7 & 28 & No & $\begin{array}{l}\text { Starch nil } \\
\text { Talc present }\end{array}$ & No barbiturate & $\begin{array}{l}\text { Methadone } \\
\text { Alcohol }\end{array}$ \\
\hline 8 & $?$ & Yes & $\begin{array}{l}\text { Starch nil } \\
\text { Talc present }\end{array}$ & No barbiturate & Morphine \\
\hline
\end{tabular}

Table I Analysis of results

${ }^{1}$ Indicates known sudden death 
cases but in none of our cases was there histological evidence of inhaled material at the lung periphery and in only one case in a major airway. Microscopically there was no acute bronchial or pulmonary infection, but there was, in general, an increase in alveolar macrophages and an impression of patchy alveolar wall thickening. Some of the thickened alveolar walls showed an inflammatory cell infiltration (Fig. 1) and an occasional giant cell aggregate not associated with any foreign material.

\section{STARCH}

Using polarized light, starch grains were identified in the small pulmonary arteries and alveolar wall capillaries in five cases; in three the starch grains were very numerous (Fig. 2). That the starch was invariably intravascular was confirmed by examination of the reticulin-stained sections. The starch grains occurred either singly or in small clumps of

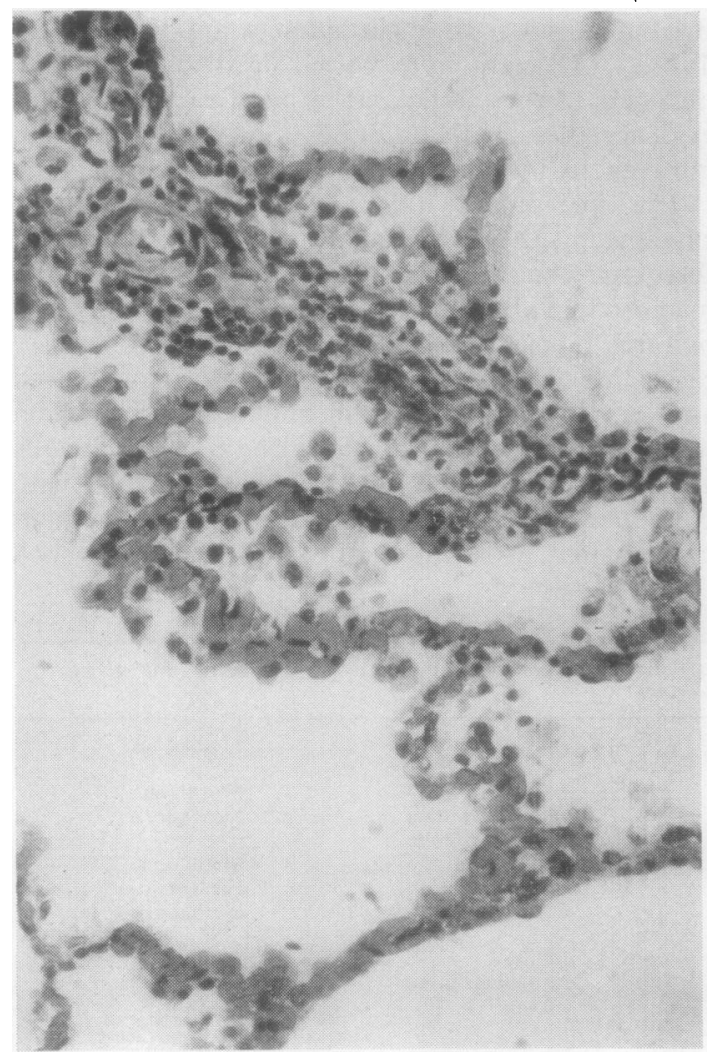

Fig. 1 . up to 10 to 12 grains, these clumps being seen in larger vessels as well as in dilated alveolar wall capillaries. Starch grains were not seen in any of the sections of kidney examined despite the large amounts of starch in the lung of the same cases.

An acute inflammatory response to starch was seen only in certain areas of the lung from case 5 in which focal areas of acute and chronic inflammatory cell infiltration of alveolar walls was seen with and without starch grains. In some such focal lesions starch grains were seen in giant cells (Fig. 3). Apart from this scanty foreign body giant cells associated with starch were seen in case 2 .

The number of starch grains present was determined for the lungs of two cases in which whole lungs were received (cases 1 and 5). The values for starch grain number per left lung were $46 \times 10^{7}$ for case 5 and $201 \times 10^{7}$ for case 1 . Taking into account that $88 \times 10^{7}$ starch grains weigh $1 \mathrm{~g}$, then the

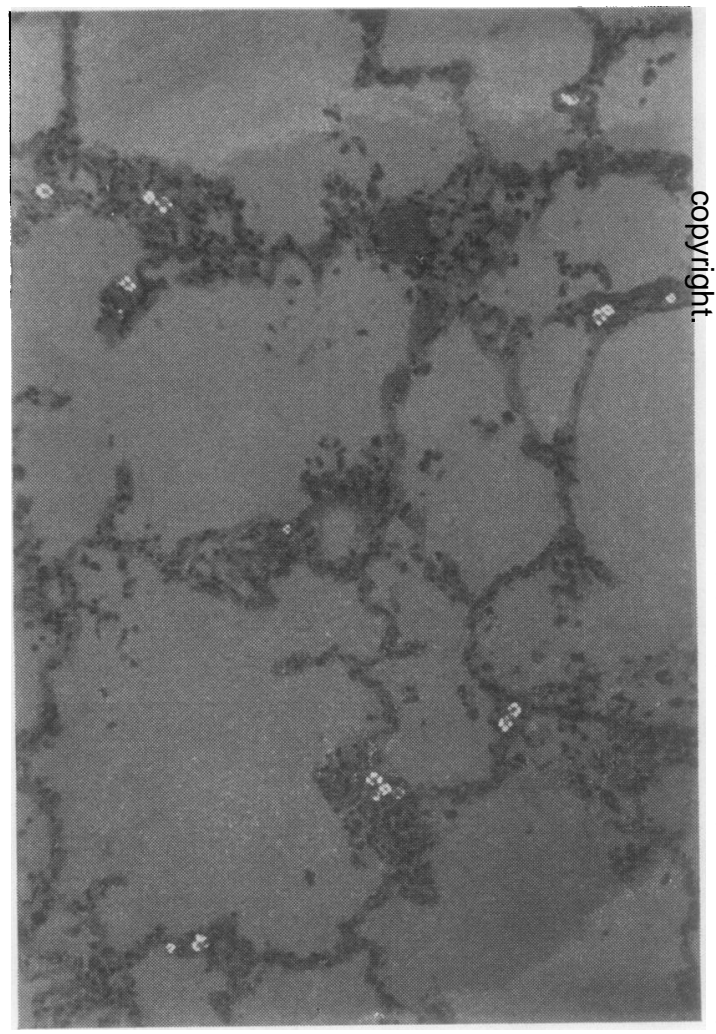

Fig. 2.

Fig. 1 Focus of interstitial acute inflammatory response with thickening of alveolar wall. No starch or talc could be identified (case 5). Haematoxylin and eosin $\times 400$.

Fig. 2 Partly polarized light. Large numbers of starch grains evenly distributed throughout the lung (case l). Haematoxylin and eosin $\times 135$. 


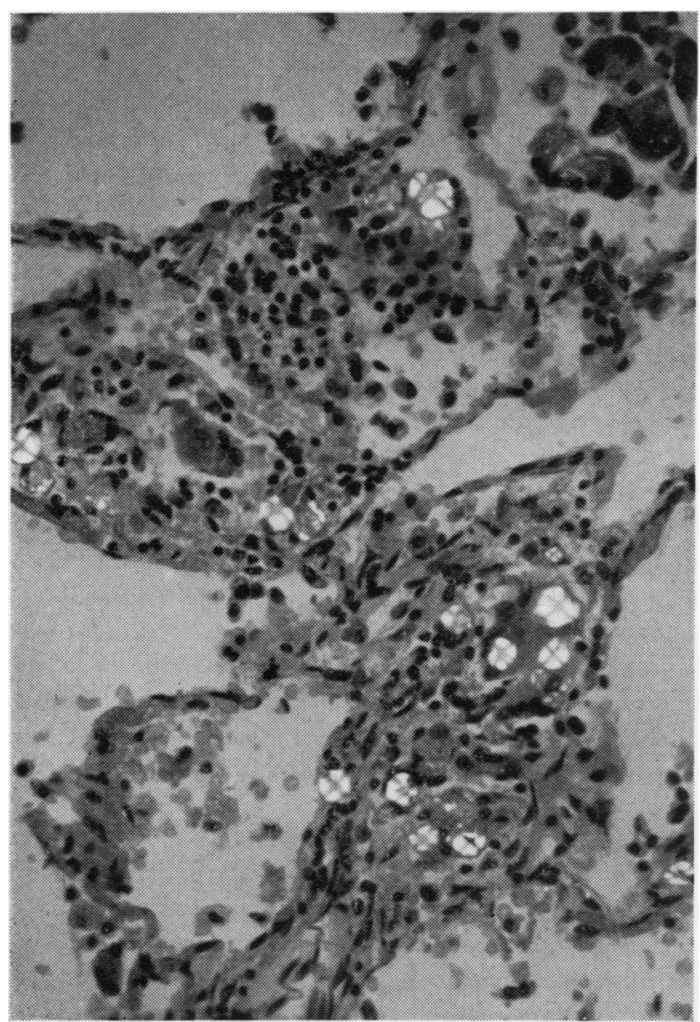

Fig. 3 Partly polarized light. Starch grains with foreign body giant cells and polymorph infiltration, the unusual finding possibly associated with infection of infected material. Similarity to the appearances in Fig. 1 (case 5). Haematoxylin and eosin $\times 400$.

weight of starch per lung was $0.52 \mathrm{~g}$ for case 5 and $2 \cdot 3 \mathrm{~g}$ for case 1 .

As high blood barbiturate levels were associated with large amounts of starch in the corresponding lung sections (Table I) without a foreign body response, it may be concluded that the starch in the lungs resulted from a single recent intravenous injection and that starch has a short intravascular life.

Animal experiments were performed to discover the fate of maize starch emboli in the lungs. Ten $\mathrm{mg}$ of starch $(40 \mathrm{mg} / \mathrm{kg})$ was injected intravenously into rats and the animals were killed at varying times after the injection. The results are shown in Figure 4. All starch grains were gone by the seventh day and the mean number of starch grains present had fallen by a factor of 10 after 24 hours (from $35 \cdot 5$ to 3.34).

No histological response to the starch emboli was seen in less than two days. After two days small foreign body giant cells were seen in association with the occasional remaining starch grains. At this time

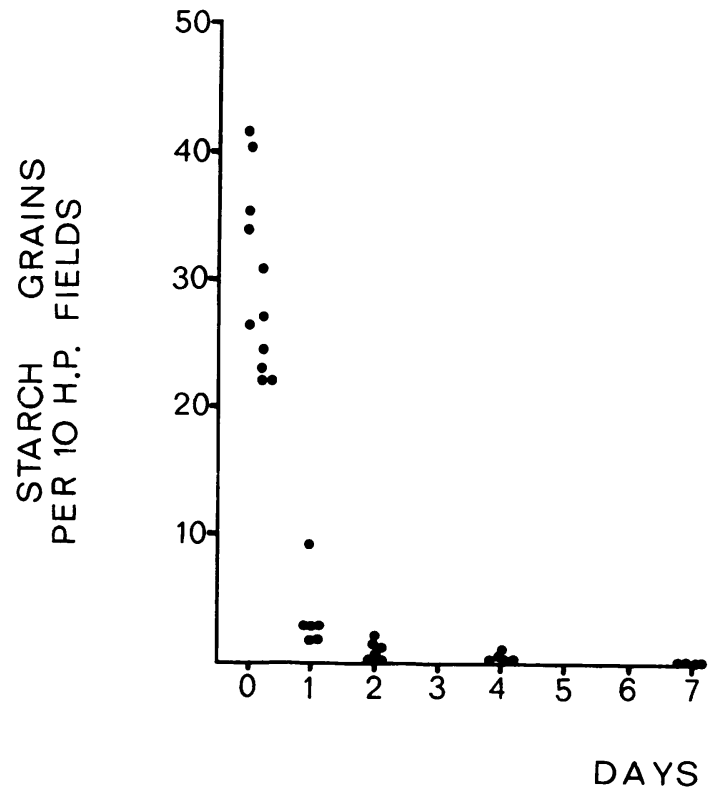

Fig. 4 The effect of time on the number of starch grains present in rat lungs after intravenous injection of $10 \mathrm{mg}$ in $0.2 \mathrm{ml}$ saline.

the starch showed up less well with polarized light having a rather fragmented appearance. No vascular thrombi were seen in any animal and there was no acute or chronic inflammatory response. The histological appearances of the lungs seven days after injection were indistinguishable from those of the non-injected control animals.

Potato starch was injected intravenously into three rats. No starch could be identified in the lungs on the seventh day after injection.

TALC

Small spicules and angular fragments of material which showed up brilliantly with polarized light were seen in all eight cases, being scanty, two or three per section, in three (cases 2, 5, and 6) and most frequent in case 7 . These fragments were almost invariably associated with a marked foreign body giant cell response (Fig. 5).

Most of the fragments of talc were recognizably within vessels of alveolar walls but there was no thrombosis or larger vessel involvement of the type recorded (Hahn et al, 1969; Krainer et al, 1962; Butz, 1969; Hopkins and Taylor, 1970).

\section{Discussion}

STARCH

Five of the eight drug addict lungs examined showed 


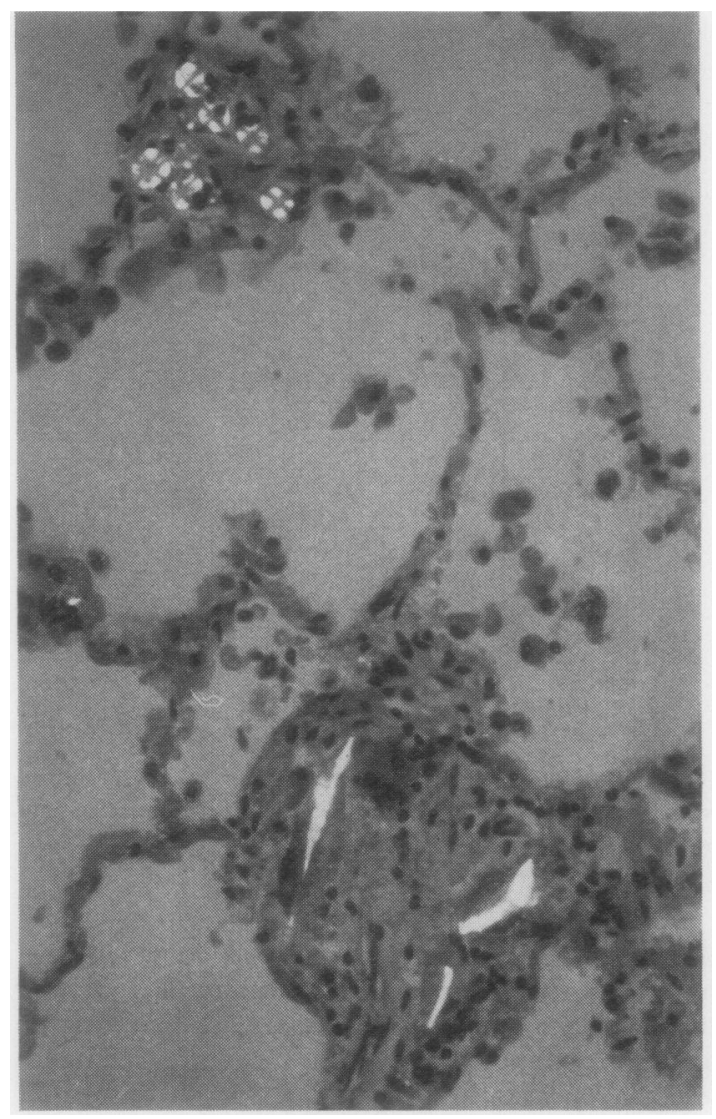

Fig. 5 Partly polarized light. Clumps of starch and adjacent clumps of refractile material; this latter has elicited a marked giant cell response (case 1). Haematoxylin and eosin $\times 400$.

the presence of starch emboli, but in none of the five was there an obvious general inflammatory or foreign body response to the starch. This absence of tissue response to starch emboli was confirmed by the rat experiments which showed a rapid removal of maize starch grains completed by day seven and that only those few starch grains present at four days showed associated giant cell formation.

It is suggested on the basis of the three rats injected with potato starch that this variety of starch is removed as quickly as maize starch.

It is well known that maize starch glove powder implanted in the peritoneum of man or animals may give rise to a clinically important foreign body reaction and adhesion formation. Experimentally such a florid response can be shown to be associated with relatively large local aggregations of starch grains or the presence of blood clot or local infection.
These factors delay removal of starch grains for a sufficient period to allow the development of a foreign body reaction. Well dispersed starch glove powder is removed from the rat peritoneum within 12 days of implantation, with most being removed in the first 48 hours (Postlethwait, McRae, Williams, Deaton, and Cornatzer, 1949; Paine and Smith, 1957). The starch emboli in this study were removed from the pulmonary circulation at an even faster rate.

Starch is a foreign body and tissues will react to it if given time. The lack of response to starch emboli in the experimental situation in rats and the minimal response in the lungs of drug addicts reflects the rapid removal of starch from the pulmonary vessels. The reports of prominent foreign body response to starch emboli (Hahn et al, 1969; Butz, 1969) were in cases where the starch was associated with predominant talc emboli that had oे elicited a characteristically severe reaction. If starch 은 were incorporated in thrombi elicited by talc, its removal would be delayed. A further variable factor between cases is the degree of sterility of injected material. Unsterile starch emboli may elicit a more marked local reaction and might explain the small foci of acute infection in alveolar walls in case 1.

Taking into account their rapid removal, starc emboli in lungs at necropsy indicate the intravenous. administration in the recent past of pharmaceutic preparations not intended for intravenous use. Starch is not specific for barbiturate preparations, and though it is included in relatively large amounts in some barbiturate preparations, it is not in others

Of 49 preparations containing barbiturates for which information was obtained from five manufacturers, 12 of 16 capsule and 20 of 33 tablet preparations included starch, 22 maize starch and 10 potato starch. The amounts varied widely, and the ratio of weight of starch to weight of barbiturate ranged from $1: 5$ to $5: 1$ for capsules and $1: 10$ to $1 \cdot 7: 1$ for tablets.

It is obvious that the amount of starch injected by an addict using the intravenous route of administration of barbiturate preparations may be very large. Thus case 5 was believed to have injected about $30 \times 60 \mathrm{mg}$ capsules of sodium amytal shortly before death. The weight of starch that could be involved, based on the manufacturers' data, ranged from 1.5 to $5.40 \mathrm{~g}$. Calculations based on starch grain counts gave a figure of $0.52 \mathrm{~g}$ of starch in the left lung. Assuming that $45 \%$ of pulmonary 0

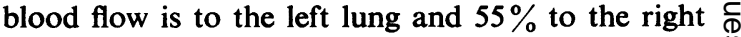
lung this would give a figure of $1.55 \mathrm{~g}$ of starch in $\stackrel{\oplus}{+}$ the lungs. This value is certainly in the range 0 suggested by the circumstantial evidence. Using the same ratio of blood flow to the left and right lungs, 
case 1 would have a total of about $5 \mathrm{~g}$ of starch.

It is interesting to speculate whether these very large numbers of microemboli could have a sufficient obstructive effect on the pulmonary circulation to contribute to the cause of death. There has been much discussion as to whether such microemboli act purely obstructively or whether there is an important reflex component (Daily, Lancaster, and Moulder, 1969; Stein, Tanabe, Khan, and Thomas, 1965; McEvoy, Harder, and Dale, 1958). However, regardless of the pathogenesis, there are some experimental data available for the fatal dose of maize starch emboli in animals. McEvoy et al (1958) found that, given as interrupted intravenous injections over a period of hours, the total dose which proved fatal in dogs varied from 125 to $332 \mathrm{mg} / \mathrm{kg}$, and in the preliminary work for our rat experiments we found that $40 \mathrm{mg}$ per $250 \mathrm{~g}$ rat was always fatal and $30 \mathrm{mg}$ occasionally so, giving the fatal dosage as 120 to $160 \mathrm{mg} / \mathrm{kg}$ for rats.

If we assume the drug addict (case 1), described as being of medium build, weighed around $70 \mathrm{~kg}$, the amount of starch found in the lungs represents a dose of $74 \mathrm{mg} / \mathrm{kg}$, not dissimilar to the fatal dose in animals. In this it must be remembered that we can only quantitate visible particulate emboli. Though starch is the major insoluble component of barbiturate preparations it is possible that the barbiturate itself is only partly dissolved in the small volume of fluid injected. The number of suspended particles which may act as emboli for a short period immediately after injection may be much larger therefore than the number of starch grains seen at necropsy.

While acute pulmonary microembolism may be a significant factor in causing death in these cases, we have no data about the effects of repeated starch embolization of the lungs. Such incidents may be the cause of the alveolar wall thickening and increased alveolar macrophage production seen in the addicts.

\section{TA L C}

The small amounts of talc present in all eight lungs examined can be evidence only for the use of the intravenous route of administration of drugs by these addicts in the past. There is no way of estimating the duration of such insoluble emboli but their presence may be of value in indicating a habit of intravenous administration. In none of our cases were talc emboli present in amounts sufficient to be of clinical significance.

The findings in the lungs of eight drug addicts dying in the London area in the last two years differ from those reported from the USA where talc appears to be found in much greater amounts.

\section{References}

Aherne, W. (1967). Methods of counting discrete tissue components in microscopical sections. J. roy. micr. Soc., 87, 493-508.

British Pharmacopoeia (1968). Pharmaceutical Press, London, pp. 1366-1368.

Butz, W. C. (1969). Pulmonary arteriole foreign body granulomata associated with angiomatoids resulting from the intravenous injection of oral medications, eg, Propoxyphene hydrochloride. J. forens. Sci., 16, 317-326.

Daily, P. O., Lancaster, J. R., and Moulder, P. V. (1965). The mechanisms of pulmonary hypertension followi:ı miliary pulmonary embolism. Surg. Gynec. Obstet., 120, 1009-1018.

Davis, H., et al (1961). Bentley's Textbook of Pharmaceutics, 7th ed., pp. 917-918. Bailliere, Tindall and Cox, London.

Glatt, M. M. (1969). The changing drug scene. Lancet, 2, 429-430.

Hahn, H. H., Schweid, A. I., and Beaty, H. M. (1969). Complicaticns of injecting dissolved methylphenidate tablets. Arch. intern. Med., 123, 656-659.

Hopkins, G. B., and Taylor, D. G. (1970). Pulmonary talc granulomatosis: a complication of drug abuse. Amer. Rev. resp. Dis., 101, 101-104.

Krainer, L., Berman, E., and Wishnick, S. D. (1962). Parenteral talcum granulomatosis: a complication of narcotic addiction. (Abstr.) Lab. Invest., 11, 671.

Lee, C. M., Jr., Collins, W. T., and Largen, T. L. (1957). A reappraisal of absorbable drug powder. Surg. Gynec. Obstet., 95, 725-737.

Lee, C. M., Jr., and Lehman, E. P. (1947). Experiments with non-irritating glove powder. Surg. Gynec. Obstet., 84, 689-695.

McEvoy, R. K., Harder, R. A., and Dale, W. A. (1958). Respiratory and cardiovascular phenomena associated with pulmonary embolism. Surg. Gynec. Obstet., 106, 271-287.

Myers, R. N., Deaver, J. M., and Brown, C. E. (1960). Granulomatous peritonitis due to starch glove powder: a clinical and experimental study. Ann. Surg., 151, 106-112.

Paine, C. G., and Smith, P. (1957). Starch granulomata. J. clin. Path., 10,51-55.

Postlethwait, R. W., McRae, J. T., Williams, R. W., Deaton, W. R., and Cornatzer, W. E. (1969). Absorbable starch glove powder. Amer. J. Surg., 78, 510-513.

Puro, H. E., Wolf, P. L., Skingandas, J., and Vazquez, J. (1966). Experimental production of human 'blue velvet' and 'red devil' lesions. J. Amer. med. Ass., 197, 1100-1102.

Stein, M., Tanabe, C., Khan, M., and Thomas, D. (1965). Pulmonary responses to macro- and micro-thromboembolism. In Pulmonary Embolic Disease, pp. 141-148, edited by A. A. Sasahara and M. Stein. Grune and Stratton, New York.

Wendt, V. E., Puro, H. E., Shapiro, J., Mathews, N., and Wolf, P. L. (1964). Angiothrombotic pulmonary hypertension in addicts-'blue velvet' drug addiction. J. Amer. med. Ass., 188, 755-757. 